\title{
A Study on Cutting Force Characteristics in Hard Turning
}

\author{
Sung Hoon Oh \\ Division of Mechanical system engineering, Chon-buk National University, Dukjin- \\ dong, Jeon-ju city, Jeollabuk-do, 561-756 \\ oshun0305@jbnu.ac.kr
}

\begin{abstract}
The competition in the processing market of the domestic machinery parts has been getting intensified along with the economic development. First, corporations are demanding aggressive activities of production cost reduction for the sake of survival rather than profit generation. Such issues as production process, production time reduction, multi-functional structural change of possessed machinery, eco-friendly process development, etc. are emerging as imminent tasks. To resolve such issues, a variety of research theses from various perspectives have been published. The problem is the diversification of the parts processing method. In other words, it is the multi-kinds \& small-scale production method. In the past, there had been an attempt to increase competitiveness through the non-cutting issues such as tool preparation time, tool replacement time, etc.; however, the time spent on the cutting process has been prolonged in recent days. Thus, there has been a demand for a direct solution as to the processing process, and the processing method by hard turning is being presented as the solution. This study analyzed the correlation of cutting force, tool abrasion, surface profile in accordance with the processing conditions using SKD11 in order to determine the optimal conditions at hard turning.
\end{abstract}

Keywords: Cutting Force, Hard Turning, Tool Wear, SKD11, CBN

\section{Introduction}

As a variety of materials and tools has been developed in addition to the development of industrial technologies, the cutting processing technology has also been developed continuously. The materials, which were developed in this way, are mostly high hard steels and they are being utilized in the automobile and machinery industries. High hard steels are generally obtained through heat processing or surface hardening, and they are defined as being approximately more than HRC45 although there is a little difference on the basis of mechanical properties. The processing of high hard steels are conducted at lathe and various machine tools; however, it is hard to do processing since they are classified as difficulttocut due to high hardness. The area of difficulttocut means the time when it is more than HRC45 as for carbon steel, alloy steel, etc., and the processing, which skips the finishing grinding process of such materials at the processing and substitutes the finishing task with the cutting process, is called hard turning[1-5]. The reason why it became possible to do hard turning without a finishing task is the emergence of the CBN (Cubic Boron Nitride) cutting tool, which was developed through powder compression molding method. CBN hard turning has an advantage of being more eco-friendly since the processing time and the tool costs are 
reduced compared to grinding and it does not use cutting oil. However, although there are such advantages, hard turning is applied to a relatively small range. This is mainly because there has been an insufficient number of studies as to exterior dignity and CBC tool abrasion after processing. The surface quality of the processed materials signifies residual stress, surface roughness and dimensional accuracy after processing and CBN tool abrasion signifies the impact of tool abrasion on surface quality. As for the CBN properties, its hardness and thermal conductivity are second best just after diamond. In addition, CBN sintering, which is equipped with ceramics coating, intensity and wear resistance, has a stronger hardness than sintered carbide and is excellent for wear resistance. Thus, it is possible to improve the lifecycle of tool significantly, and that it is possible to do the precise finishing is the largest advantage of CBN. Furthermore, it is the quality of material that can obtain the modest surface intensity of illumination through the combination of the basic material. Therefore, the cutting tool, which used CBN as the material, had garnered the attention as the tool customized for high-speed cutting [6-10]. However, CBN, which is recently being utilized as the cutting tool customized for the high-level precision hard turning finishing processing, does not react to steel well unlike diamond; therefore, it is possible to apply it to the processing of high hard steel or the high-speed processing of cast iron. In particular, hardness of about HRc 55 is maintained even at $1000^{\circ} \mathrm{C}$ during the processing; thus, it is being utilized widely in the high speed processing, the processing of heat-processed steel, etc. [10] then, SKD 11, which is generally used, is a high C-high $\mathrm{Cr}(1.5 \% \mathrm{C}-13 \% \mathrm{Cr})$ steel; in other words, it is the same as that carbon is inlaid in a stainless steel of 13 chrome; thus, it is known that it is strong against rust. As for the quantity of carbide, it has the largest quantity among the tool steels, and it has wear resistance at room temperature. Thus, its machinability is not very good. This study analyzed the correlation of cutting force, tool abrasion, surface profile and residual stress in accordance with the processing conditions using SKD 11 in order to determine the optimal conditions at hard turning.

\section{Experimental Devices}

The experimental devices used in this experiment are shown in Table 2-1.

Table 2.1. Experimental equipments

\begin{tabular}{c|l}
\hline \hline NC lathe & Model : HWACHEON HL460×1000GN \\
\hline Tool dynamometer & model : KISTLER 9257A range : 5000N resolution : 0.01N \\
\hline Charge amplifier & model : KISTLER 5001 range : $\pm 500000 \mathrm{pc}$ output voltage $: \pm 10 \mathrm{~V}$ \\
\hline A/D converter & FPGA ASIC controller \\
\hline Computer & Intel PentiumIV processor $3.0 \mathrm{GHz}, 1024 \mathrm{~GB}$ RAM \\
\hline Surface roughness tester & Mitutoyo Surftest-301 \\
\hline \hline
\end{tabular}

A tool dynamometer was installed in order to measure the cutting force generated between the tool and the processed materials, and a jig was designed, manufactured and installed in order to install the tool on top of the tool dynamometer. Figure 2-1 shows the photo of the equipment used in this experiment and Figure 2-2 shows the configuration of the experimental devices. 


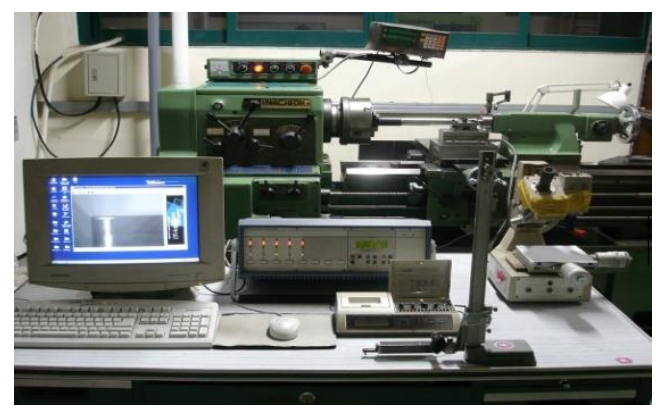

Figure 2.1. Experimental configuration

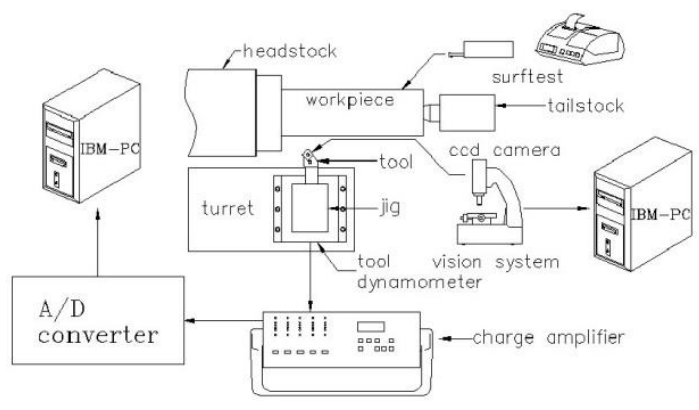

Figure 2.2. Experimental device set up

The material used in this experiment is SKD 11 that is a high hard steel, and it is one of the general-purpose steels that is widely used as accounting for a majority of the cold-formed tool steels. Its diameter is $\mathrm{d}=45 \mathrm{~mm}$, and it was cut with the length of $\mathrm{L}=280 \sim 340 \mathrm{~mm}$ in consideration with the cutting speed and the transfer ratio. The chemical property, formation and size of the material are shown in Table 2-2.

Table 2-2. Chemical compositions of workpiece

\begin{tabular}{|c|c|c|c|c|c|c|c|c|c|}
\hline $\begin{array}{l}\text { Composition(\%) } \\
\text { Material }\end{array}$ & $\mathrm{C}$ & $\mathrm{Si}$ & $\mathrm{Mn}$ & S & $\mathrm{P}$ & $\mathrm{Cr}$ & Mo & $\mathrm{Ni}$ & V \\
\hline SKD 11 & $\begin{array}{l}1.40 \\
\sim \\
1.60\end{array}$ & $<0.40$ & $<0.60$ & $<0.30$ & $<0.30$ & $\begin{array}{c}11.0 \\
\sim \\
13.0\end{array}$ & $\begin{array}{c}11.0 \\
\sim \\
13.0\end{array}$ & $\begin{array}{l}0.80 \\
\sim \\
1.20\end{array}$ & $\begin{array}{l}0.20 \\
\sim \\
0.50\end{array}$ \\
\hline
\end{tabular}

As for the test piece, it was arranged so that the surface hardness would maintained about HRC 58 through the heat processing of $700^{\circ} \mathrm{C}$. PCBN (Polycrystalline Cubic Boron Nitride) tool, which was used in this experiment, has a very similar structure to diamond, and it is synthesized through presintering with high temperature of $1400 \sim 1500{ }^{\circ} \mathrm{C}$ and high pressure of $5 \sim 7 \mathrm{GPa}$. PCBN is created by mixing $\mathrm{Co}$, TiC, TiN and other materials with the presintered $\mathrm{CBN}$. In general, $\mathrm{CBN}$ tool is classified depending on the containment quantity of $\mathrm{CBN}$; if CBN content is more than 90 percent, it is called high CBN and if CBN content is less than 70 percent, it is called low CBN. In general, high CBN is added by TiC or TiN and low CBN is added by Co. The chemical properties of the tool is shown in Table 2-3 and the properties of the tool material is shown in Table 2-4. The formation of the tool is shown in Figure 2-3. 
Table 2-3. Chemical compositions of PCBN

\begin{tabular}{|c|c|c|c|c|c|c|c|c|c|c|}
\hline $\begin{array}{c}\text { Composition(\%) } \\
\text { Material }\end{array}$ & $\mathbf{O}$ & $\mathbf{A l}$ & $\mathbf{C a}$ & $\mathbf{T i}$ & $\mathbf{C r}$ & $\mathbf{F e}$ & $\mathbf{C o}$ & $\mathbf{W}$ & At & $\mathbf{V}$ \\
\hline $\begin{array}{c}\text { low CBN } \\
\text { (TB650) }\end{array}$ & 13.10 & 7.51 & & 65.81 & & 10.08 & & 2.88 & & 0.61 \\
\hline
\end{tabular}

Table 2-4. Material properties for tools

\begin{tabular}{c|c}
\hline \hline Material properties & TB650 \\
\hline \hline Density $\left(\mathbf{k g} / \mathbf{m}^{\mathbf{3}}\right)$ & 4.3 \\
\hline Thermal conductivity $\left(\mathbf{W} / \mathbf{m}^{\circ} \mathbf{K}\right)$ & 44 \\
\hline Coefficient of Thermal Expansion $/{ }^{\circ} \mathbf{C} \times \mathbf{1 0}^{-\mathbf{6}}$ & 4.7 \\
\hline Young's Modulus $(\mathbf{G P a})$ & 587 \\
\hline Poisson's rate & 0.15 \\
\hline Hardness $(\mathbf{H v})$ & 3000 \\
\hline \hline
\end{tabular}
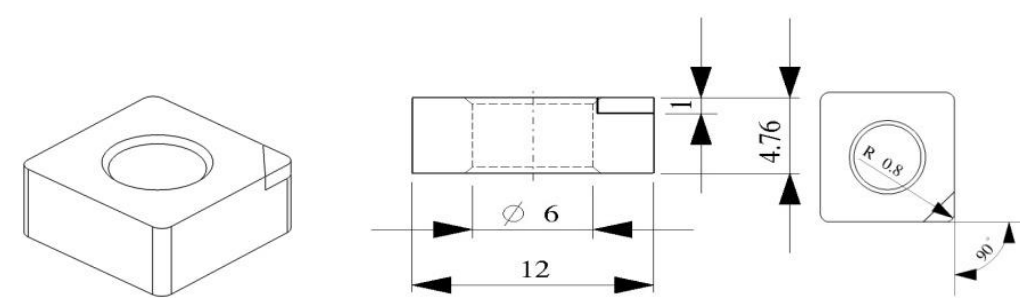

Figure 2-3. Shape and dimensions of specimen

\section{Results and Consideration}

In order to determine how the cutting tendency would be changed depending on the cutting conditions at the cutting of SKD 11 (HRc 58), the surface roughness of the processed surface, the tool abrasion and the variation feature of cutting force were examined based on the conditions of cutting speed $(1010,710,510 \mathrm{rev} / \mathrm{min})$ and transfer ratio $(0.193,0.157,0.079$ $\mathrm{mm} / \mathrm{rev}$ ). Fig. 3-1 summarized all the average cutting forces measured in each condition in one graph so that they would be easily compared. The size of average cutting forces was in the order of tagential force, distribution force and transfer force. This result matches the general cutting processing theory. However, it is possible to observe the results from several documents in which distribution force was greater. This can be explained that it may be subject to change depending on the processing conditions and the type of machinable material. 


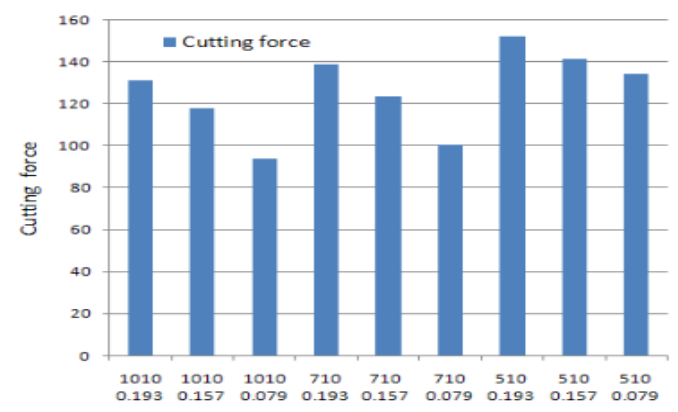

Figure 3-1(a) Cutting force of each condisions

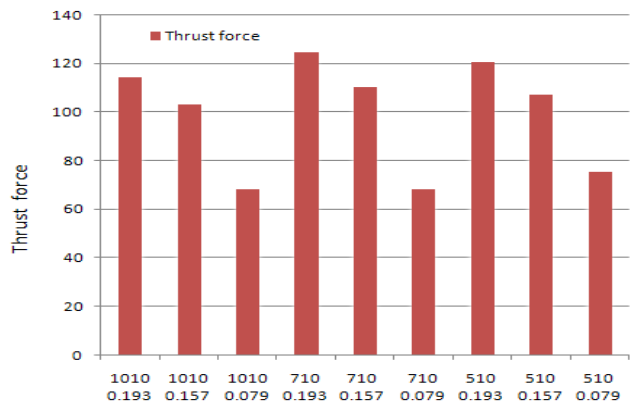

Figure 3-1(b) Thrust force of each condisions

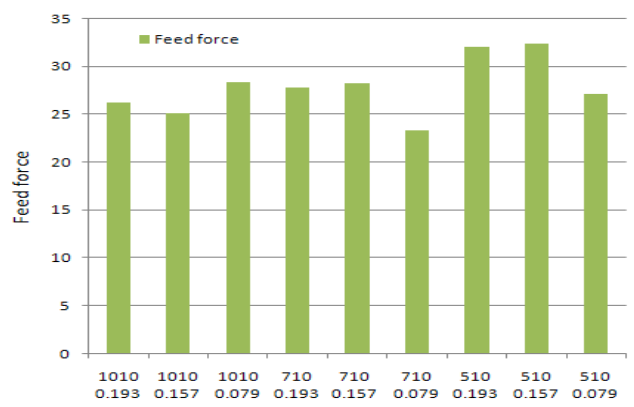

Figure 3-1(c) Feed force of each condisions

Figure 3-2, Figure 3-3 and Figure 3-4 show the beginning value and end value of the three cutting force components depending on the processing conditions. The cutting force had increased as the tool abrasion was progressing. The reason is that the cutting tool was able to maintain its sharpness at the beginning and had an insignificant reaction to the impact of the cutting heat, etc. generated by cutting; however, it was more exposed to the impact of heat and friction since the size of the contact surface between the tool and the processed material as the tool abrasion got enlarged. And SKD 11 was cut by the high CBN tool, but the measurement was actually insignificant since the tool abrasion became $0.25 \mathrm{~mm}$ within 3 minutes. This result was also significantly different from the experiment of AISI 52100 steel. As for the experiment of AISI 52100 steel, the measured values for the cutting by the high CBN were different for each condition; however, the tool abrasion was almost $0.25 \mathrm{~mm}$ when 
cutting for about 10 to 30 minutes. This is high CBN when comparing the AISI 52100 (HRc 62) with SKD 11 (HRC 58); this means that it had a better processing capability although the AISI 52100's hardness was higher when conducting the processing by high CBN. Thus, the cutting capability is not only determined by hardness but also influenced by properties or other factors. If the processing goes smoothly by turning high hard steels, it will be possible to obtain an effect of substituting the grinding that has been primarily conducted so far. For this, it is required to have a small depth of cut and transfer, and it is imperative to maintain modest surface quality after processing. Since a small depth of cut and transfer speed causes a reduction of cutting force and it has a relatively larger rate of change compared to the general cutting and also there is an impact of vibration, it is difficult to measure the cutting force accurately. Thus, this experiment minimized the effects having a large rate of change through measuring average tagential force, average distribution force and average transfer force in accordance with each condition.

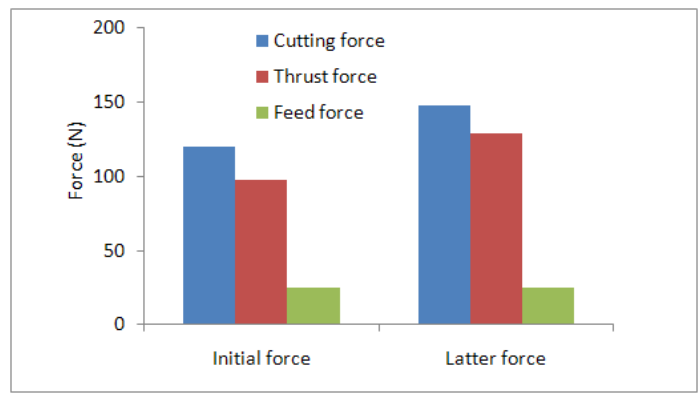

Figure 3-2(a) Initial and Latter force for cutting condition ( $v=1010 \mathrm{rev} / \mathrm{min}$, $\mathrm{f}=0.193 \mathrm{~mm} / \mathrm{rev}$ )

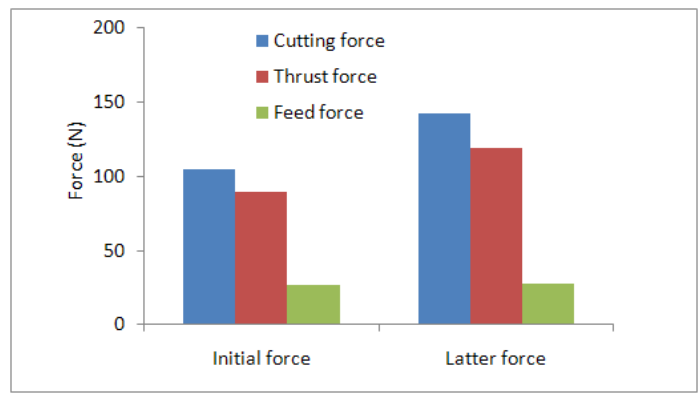

Figure 3-2(b) Initial and Latter force for cutting condition (v=1010 $\mathrm{rev} / \mathrm{min}$, $\mathrm{f}=0.157 \mathrm{~mm} / \mathrm{rev}$ )

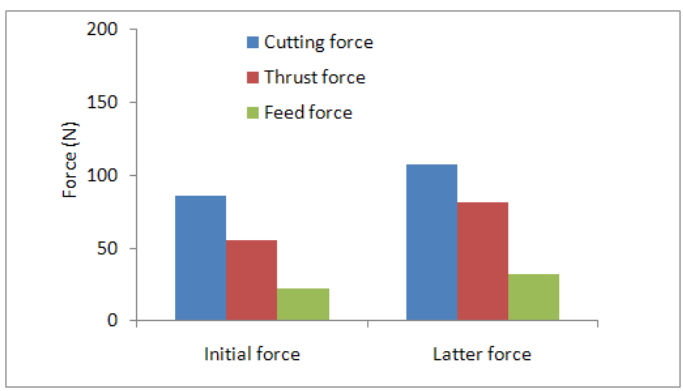


Figure 3-2(c) Initial and Latter force for cutting condition (v=1010 rev/min, $\mathbf{f}=0.079 \mathrm{~mm} / \mathrm{rev}$ )

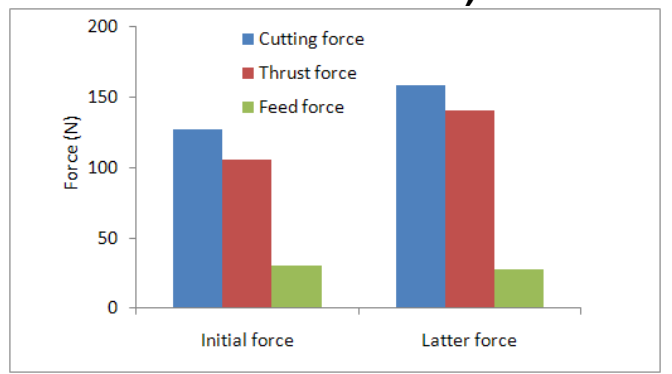

Figure 3-3(a) Initial and Latter force for cutting condition ( $v=710 \mathrm{rev} / \mathrm{min}, f=0.193$ $\mathrm{mm} / \mathrm{rev}$ )

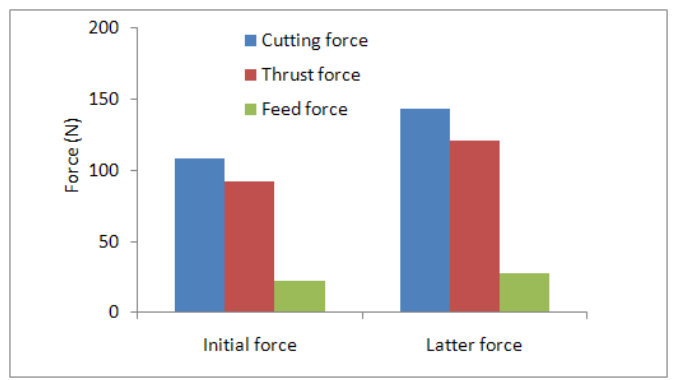

Figure 3-3(b) Initial and Latter force for cutting condition (v=710rev/min, $\mathrm{f}=0.157 \mathrm{~mm} / \mathrm{rev}$ )

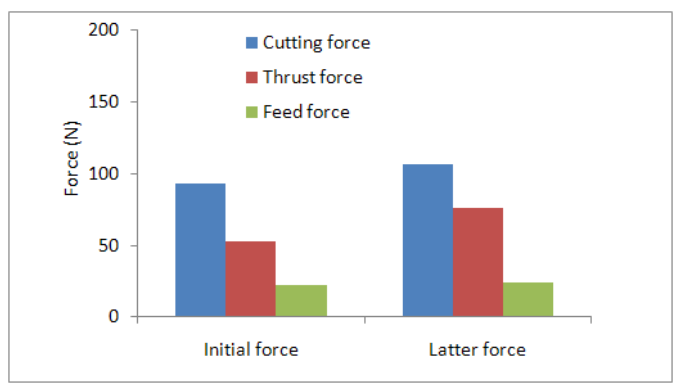

Figure 3-3(c) Initial and Latter force for cutting condition ( $v=710 \mathrm{rev} / \mathrm{min}, \mathrm{f}=\mathbf{0 . 0 7 9}$ $\mathrm{mm} / \mathrm{rev}$ )

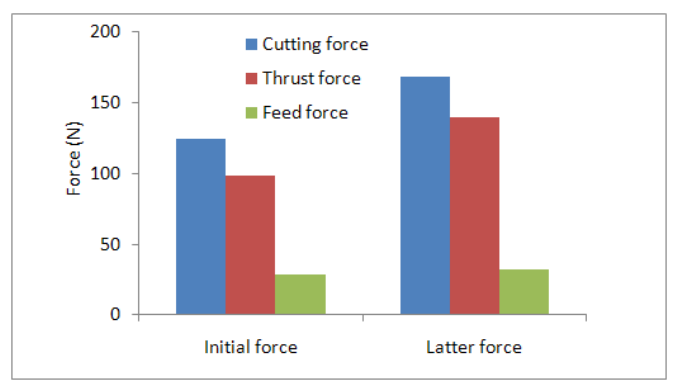

Figure 3-4(a) Initial and Latter force for cutting condition ( $v=510 \mathrm{rev} / \mathrm{min}, f=0.193$ $\mathrm{mm} / \mathrm{rev}$ ) 


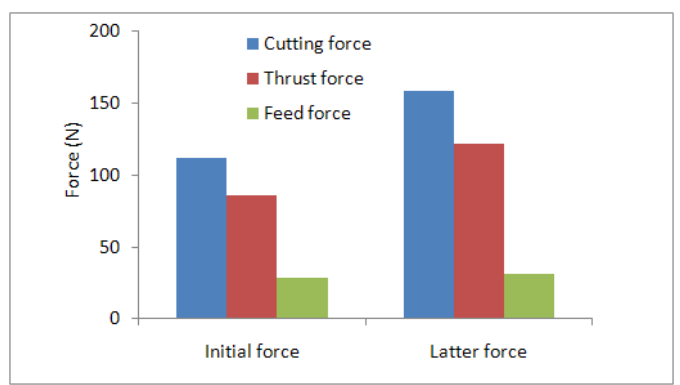

Figure 3-4(b) Initial and Latter force for cutting condition (v=510rev/min, $\mathrm{f}=0.157 \mathrm{~mm} / \mathrm{rev}$ )

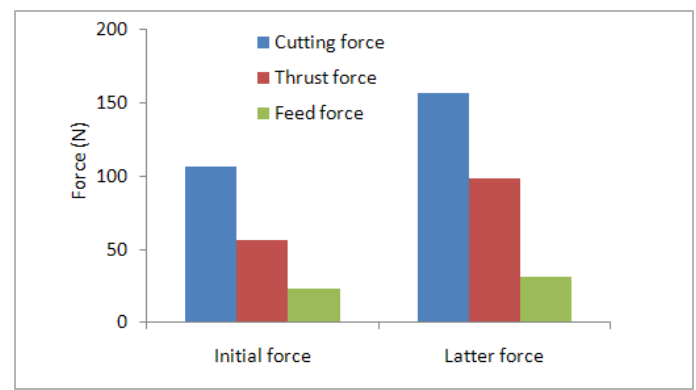

Figure 3-4(c) Initial and Latter force for cutting condition ( $v=510 \mathrm{rev} / \mathrm{min}, f=0.079$ $\mathrm{mm} / \mathrm{rev}$ )

Figure 3-5 shows the average cutting force aspect in accordance with transfer speed under the condition of cutting speed being $75 \sim 130 \mathrm{~m} / \mathrm{min}$. As for the average cutting force, it selected the average value divided by square root upon adding the cutting force of each property that had been raised to the second power. As shown in the picture, it is possible to observe the reduction of cutting force in accordance with the reduction of transfer ratio when the cutting speed was constant and the increase of cutting force in accordance with the reduction of cutting speed when the transfer ratio was constant. This is because the volume to be cut increases in accordance with an increase of transfer speed, and it is possible to know that the impact of transfer speed is very significant even at high hard steel cutting. It shows the tendency in which distribution force decreases a bit or remains constant in depending on the increase of cutting speed; this is because the temperature between the tool and the processed material rose due to the increase of speed; thus, even cutting of high hardness is possible with a small cutting force. Moreover, it is interpreted that a friction resistance did not occur since a build-up edge was not generated at a cutting speed of faster than $120 \mathrm{~m} / \mathrm{min}$. Thus, it is possible to know that it is appropriate to maintain a cutting speed of faster than $120 \mathrm{~m} / \mathrm{min}$ as a processing condition for turning of high hard steels and select the condition that is lower than $0.157 \mathrm{~mm} / \mathrm{rev}$ as for transfer speed in terms of conducting a smooth cutting. 


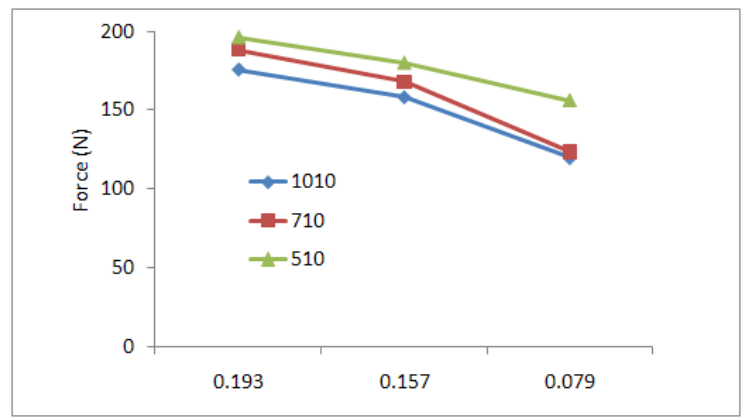

Figure 3-5(a) The effect of feed rate on the cutting force

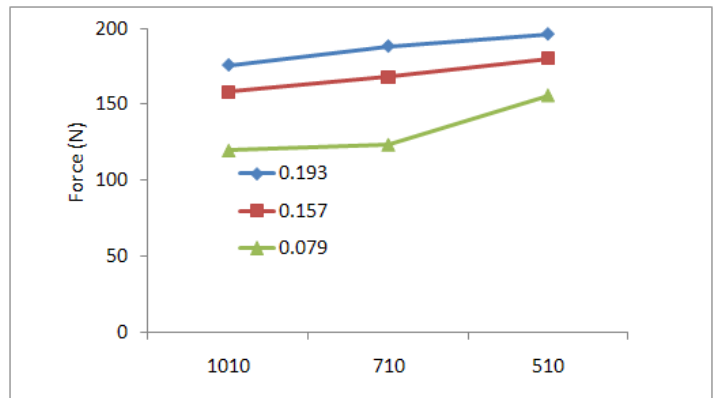

Figure 3-5(b) The effect of cutting speed on the feed rate

Figure 3-6 shows the cutting quantity per each condition. As for the expensive price of CBN tool, it is very important for general corporations to know how much they can conduct cutting until the lifetime of a tool. Thus, the cutting quantity was calculated when the tool abrasion length became $0.21 \mathrm{~mm}$. As a result, it was possible to find out that the cutting quantity was larger with lower cutting speed and higher transfer ratio. Thus, it would be possible to conduct an economic and efficient processing if considering cutting force and cutting quantity at the same time when determining the processing conditions in the actual industrial site.

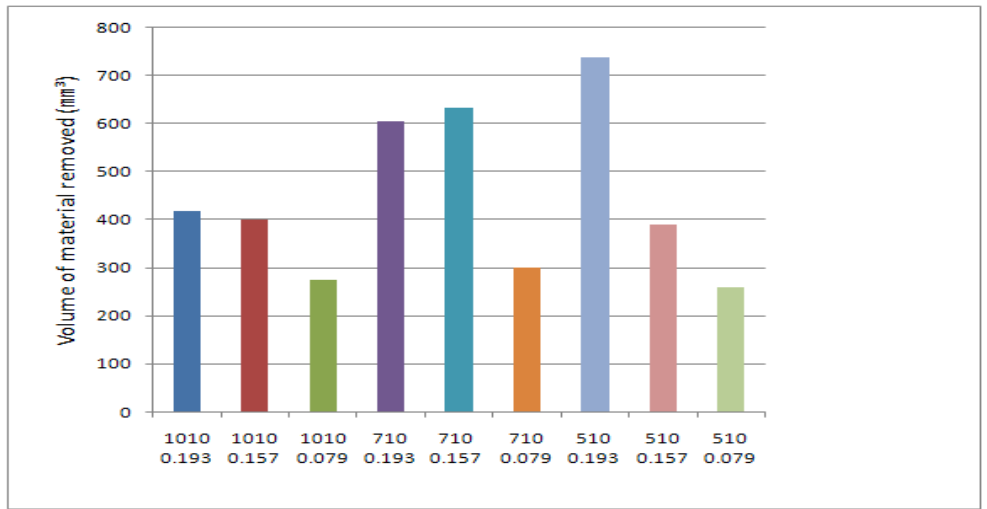

Figure 3-6. Variation of the volume of material removal $\mathrm{W}$ with cutting speed and feed 


\section{Conclusion}

This study examined the cutting force in order to determine the processing properties at hard turning of SKD 11 high hard steels. The following conclusions could be deducted through examining the impacts in accordance with the cutting conditions for turning cutting of high hard steels and determining more clearly the relationship between the cutting conditions.

1. It was possible to observe the tendency that the size of tagential force and distribution force in all the conditions got larger as the tool abrasion was progressing. Transfer force consistently showed a certain size regardless of the progress of tool abrasion.

2. It was confirmed that it was effective to do cutting with low cutting speed and high transfer ratio in order to cut a large quantity at the cutting of SKD 11. It was analyzed that it was due to the drastic tool abrasion because the emission of cutting heat at high cutting speed and low transfer ratio in consideration with the property of SKD 11 of having a strong wear resistance.

\section{References}

[1] T. G. Dawson, "Machining Hardened Steel with Ploycrystalline Cubic Boron Nitride Cutting Tools", Georgia Institute of Technology, (2002) June 14.

[2] H. K. Toenshoff, C. Arendt and R. B. Amor, "Cutting hardened steel", Annals of CIRP, vol. 49, no. 2, (2000), pp. 1-19.

[3] T. G. Dawson and T. R. Kurfess, "Quantification of Tool Wear using White Light Interfermetry and Three dimensional Computational Metrology", International Journal of Machine Tools \& Manufacture, (2004), pp. $1-6$.

[4] T. J. Ko and H. S. Kim, "Surface Integrity and Machinability in Intermittent Hard turning", The International Journal of Advanced Manufacturing Technology, vol. 18, (2001), pp. 168-175.

[5] Y. K. Chou and M. Barash, "Review on Hard Turning and CBN Cutting Tools", SME Technical Paper, Proceedings of the 1st International Machining and Grinding Conference, MR95-214, (1995), pp. 951-962.

[6] J. A. Arsecularatne, L. C. Zhang and C. Montross, "On Machining of Hardened AISI D2 Steel with PCBN Tools", Journal of Materials Processing Technology, vol. 171, (2006) January, pp. 244-252.

[7] M. Remadna and J. F. Rigal, "Evolution During Time of Tool Wear and Cutting Forces in the Case of Hard turning with CBN Inserts", Journal of Materials Processing Technology, vol. 178, no. 14, (2006) September, pp. 67-75.

[8] S. H. Oh and B. M. So, "Internal grinding characteristics with ceramic and CBN in Nitriding treated steel", International Journal of Control and Automation, vol. 5, no. 3, (2012) September, pp. 287-291.

[9] E. Zeren and T. Ozel, "Hard turning technology", Report No. MRAL-01, Rutgers" Engineering, (2002) June.

[10] S. H. Oh, "Dressing Characteristics in Nitiriding treated bearing steel under ceramic wheel grinding conditions", International Journal of Control and Automation, vol. 5, no. 3, (2012) September, pp. 133-139.

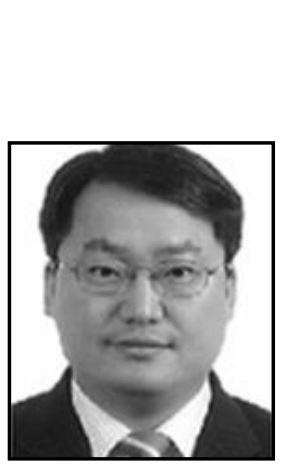

\section{Author}

\section{Author's Name: Sung Hoon Oh}

Author's profile.

Professor, Division of Mechanical system engineering, Chon-buk

National University, Dukjin-dong, Jeon-ju city, Jeollabuk-do, 561756 E-mail: oshun0305@jbnu.ac.kr 